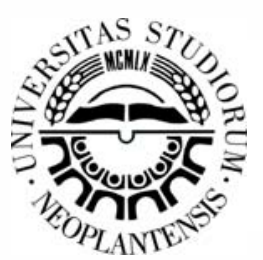

\title{
Laser Welding Parameters Effect on the Weld Metals Properties at Duplex Stainless Steels
}

\author{
Enikö Réka Fábián \\ Óbuda -University, Donát Bánki Faculty of Mechanical and Safety Engineering, \\ 1034 Budapest Népszínház street 8, Hungary
}

\begin{abstract}
Nd: YAG laser welding of duplex stainless steels as 2205, LDX 2101, 2304, LDX 2404 grades were performed with and without addition materials. As additional material were used Metco 41C high nickel contain powder and $2293 \mathrm{NL}$ filler wire, conventional used for standard duplex stainless steels. The mechanical and corrosion properties of duplex stainless steels welds are dependent on microstructure and chemical composition. The additional materials favourable effects on mechanical properties were observed. The best pitting corrosion resistance were observed at specimens welded with wire addition.
\end{abstract}

Key words: Laser beam, duplex stainless steel, additional material, microstructure.

\section{INIRODUCTION}

Laser welding technique is widely used in several industries such as automotive, aerospace, and medical industries as well as electrical devices. The laser welding requires a low heat input during welding, which results in a higher capability of combining heat-susceptible parts with low distortions. The small focusing zone of laser welding is the main reason for its wide application in cropping narrow welding zones with low heat involvement. Additionally, the welded beads from laser welding processes are created with limited residual stress and deformation [1]. Although laser welding has been used for several decades now, significant and exciting innovations often arise from both the process and / or materials side.

Duplex stainless steels (DSS) are widely used in the oil, chemical and medical industry due to favourable microstructure and chemical composition. The advantageous characteristics of duplex stainless steels are guaranteed by a balanced austenite / delta-ferrite distribution with minimum possible amount of secondary phases in the microstructure. The ferrite offers high strength and resistance to stress corrosion cracking while the austenite contributes both good ductility and general corrosion resistance [2]-[5]. Welding may deteriorate the optimum microstructure of duplex stainless steels [6] -
[9], and in this way toughness and corrosion resistance of the weld metal (VM) and heat affected zone (HAZ) may deteriorate [10]. All duplex stainless steels solidify as primary ferrite solidification mode and austenite forms by solid state transformation. When temperature drops below ferrite solvus temperature, ferrite begins to transform to austenite. This transformation ultimately determines ferrite-austenite balance in the final weld metal. The nature of ferrite-austenite transformation is dependent on steel composition, additional materials, if exist and cooling rate. Autogenously welding normally causes higher ferrite content compared to the parent metal due to insufficient austenite reformation. Pekkarien et al. observed when solidification and cooling rate are high, austenite formation decrease [11]. The properties which are normally considered as benefits when laser welding, the low heat input and the rapid cooling rate, often seen as disadvantages when welding duplex steels because excessive ferrite contents in weld metal and HAZ. The heat inputs can be modified by welding speed, focus point of laser beam and by additional materials. The objective of this work was to determine how the austenite reformation, mechanical properties and pitting resistance of different duplex stainless steels are affected by use of filler wire or austenitic powder additions during diode pumped Nd:YAG laser.

\footnotetext{
* Corresponding author's.e-mail: fabian.reka@bgk.uni-obuda.hu
} 


\section{Materials AND Processing}

In this work the weld metals characteristics were studied after laser beam welding of four different duplex stainless steels specimens (70x120 mm) with different thicknesses. The used DSS steels were produced at Outokumpu Works. The chemical composition and the thickness of the sheets are presented in Table 1.

Table 1 Chemical composition of the parent materials

\begin{tabular}{|c|c|c|c|c|c|c|c|c|c|c|c|c|c|}
\hline \multicolumn{2}{|c|}{ Steel } & \multirow{2}{*}{$\begin{array}{c}\text { Thickness } \\
\text { (mm) }\end{array}$} & \multicolumn{11}{|c|}{$\begin{array}{c}\text { Chemical } \\
\text { composition\% }\end{array}$} \\
\hline Grade & EN No. & & $C$ & $S i$ & $M n$ & $P$ & $S$ & $\mathrm{Cr}$ & $N i$ & Mo & $N$ & $C u$ & $F e$ \\
\hline 2205 & 1.4462 & 1.5 & 0.019 & 0.37 & 1.42 & 0.022 & 0.001 & 22.4 & 5.8 & 3.16 & 0.177 & - & rest \\
\hline $\begin{array}{l}\text { LDX } \\
2101 \\
\end{array}$ & 1.4162 & 1.5 & 0.023 & 0.66 & 4.97 & 0.022 & 0.001 & 21.49 & 1.51 & 0.29 & 0.228 & 0.25 & rest \\
\hline 2304 & 1.4362 & 2.5 & 0.018 & 0.30 & 1.37 & 0.024 & 0.001 & 23.16 & 4.71 & 0.34 & 0.12 & 0.27 & rest \\
\hline $\begin{array}{c}\text { LDX24 } \\
04\end{array}$ & 1.4662 & 3 & 0.025 & 0.36 & 3.00 & 0.022 & 0.001 & 23.92 & 3.66 & - & 0.279 & - & rest \\
\hline
\end{tabular}

The DSSs such as standard duplex 2205 (X2CrNiMoN2253) and lean duplex LDX 2101 (X2CMnNiN21-5-1), 2304 (X2CrNiN23-4) are widely used as structural materials for piping, heat exchangers, pressure vessels etc. [6], [12]. The LDX 2404 steel (X2CrNiMnMoCuN 24-43-2) appear in British standards (BS EN 10088-2:2014) in 2014. The grade combines a higher mechanical strength than for other common duplex grades with a generally high corrosion resistance [13]. To characterize the stainless steels pitting corrosion resistance it used to calculate the pitting resistance equivalent (PRE)

$\mathrm{PRE}=\mathrm{Cr}+3.3(\mathrm{Mo}+0.5 \mathrm{~W})+16 \mathrm{~N}$

The LDX2404 steel has similar high pitting resistance equivalent as the standard 2205 steel (Table 2).

Table 2 Pitting resistance equivalents of the parent materials

\begin{tabular}{|c|c|c|c|c|}
\hline EN NR. & 1.4162 & 1.4362 & 1.4662 & 1.4462 \\
\hline Steel & LDX2101 & 2304 & LDX240 & 2205 \\
\hline PRE & 26 & 28 & 33 & 35 \\
\hline
\end{tabular}

Table 3 Chemical composition of additional materials

\begin{tabular}{|c|c|c|c|c|c|c|c|}
\hline \multirow{2}{*}{$\begin{array}{c}\text { Additional } \\
\text { material }\end{array}$} & $\boldsymbol{C r}$ & $\mathbf{N i}$ & $\mathbf{M o}$ & $\boldsymbol{S i}$ & $\boldsymbol{N}$ & $\boldsymbol{C}$ & $\boldsymbol{F e}$ \\
\cline { 2 - 7 } \\
\hline $\begin{array}{c}\text { Metco 41C } \\
\text { powder }\end{array}$ & 17 & 12 & 2.5 & 2.3 & - & 0.03 & rest \\
\hline $2293 \mathrm{LN}$ & 22.5 & 8.5 & 3.0 & 0.5 & 0.15 & 0.02 & rest \\
\hline
\end{tabular}

Welding was performed with a $2.5 \mathrm{~kW}$ Rofin DY027 diode pumped Nd:YAG laser on milled edges in butt joints without gap. The applied laser power was $2500 \mathrm{~W}$. To realize correspondent welded joints the applied welding speed had been determinate by parent material thickness and their chemical composition. The powder feeding was performed applying the self-feeding Sultzer Metco apparatus (Fig. $1 \mathrm{c}, \mathrm{d}$ ). With this apparatus it could be realized $15 \mathrm{~g} / \mathrm{min}$ powder addition. High nickel content iron based metal powder (Metco41C from Sulzer Metco) and a conventional used wire for duplex stainless steels $2293 \mathrm{NL}$ with $0.8 \mathrm{~mm}$ diameter were used as additional material. Chemical compositions of additional materials are presented in Table 3 .
Both the shielding gas and backing gas were argon, which has no effect on the austenite/ferrite ratio in molten metal [14] - [17].
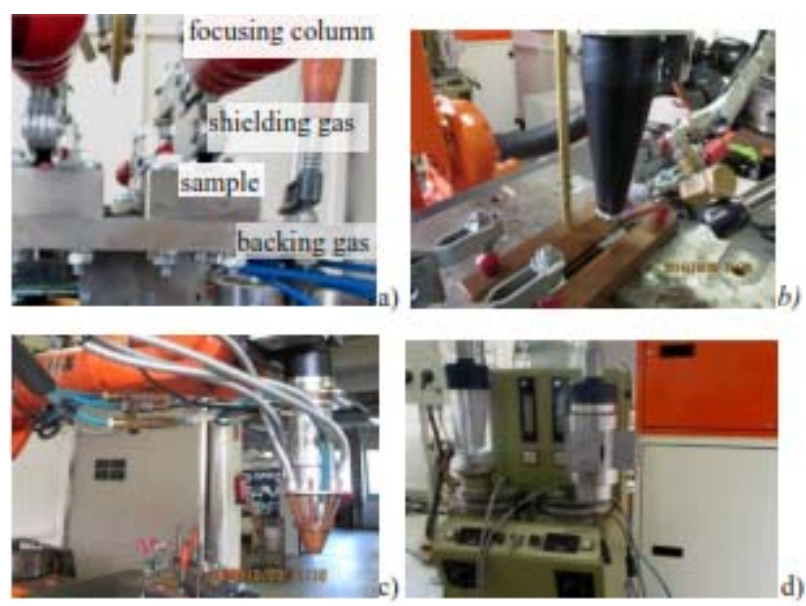

Fig. 1 Instalation for this work a) arreangement of the experiment $b$ ) wire position in front of laser beam c) head of powder additioner concentric with laser power column d) Sultzer Metco powder selffeeding

Welded joints were metallographic studied in cross sections after visual inspection. The microstructures and phases in the weld metal were analysed by Olympus PMG3 inverse microscope. Microstructural features of the different regions of the welded joint were characterized by conventional metallographic practices using Kalling'2 reagent $\left(100 \mathrm{ml} \mathrm{H}_{2} \mathrm{O}+100 \mathrm{ml} \mathrm{HCl}+5 \mathrm{~g} \mathrm{CuCl}_{2}\right)$, which attack ferrite and slightly attack austenite. Weld metals after laser welding are as narrow that phase ratio quantification cannot be used magnetic induction based feritscopes. This narrow region causes uncertainty at the positioning of the probe, and the excited volume is usually greater since the feritscope is also measuring either basic material as a part of the weld metal results. The standard ISO 8249:2000 for 
determination of ferrite number in duplex ferriticaustenitic stainless steel weld metals recommend smooth surface preparation which shall be not less than $5 \mathrm{~mm}$ in width .For this reason for quantitative analysis of the microstructure (austenite/delta-ferrite distribution) Beraha'2 reagent $(85 \mathrm{ml}$ water, $15 \mathrm{ml} \mathrm{cc}$. $\mathrm{HCl}$ and $1 \mathrm{~g}$ $\mathrm{K}_{2} \mathrm{~S}_{2} \mathrm{O}_{5}$ ) was used. Beraha'2 reagent colours ferrite but not austenite, due to deposit a sulphide based interference film on the specimen. It provides a sufficiently high contrast of the ferrite and austenite phases although the colour intensity differs in case of different parent materials and/or additional materials. The appearance of the microstructure of weld metal after these etching materials is visible in Fig. 2.
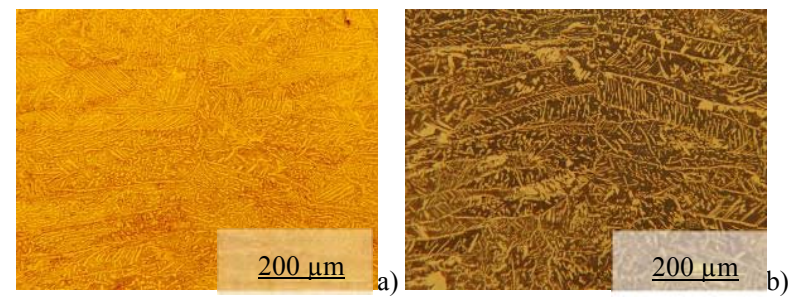

Fig. 2 The microstructure of weld metal of 2304 steel after welding with $14 \mathrm{~g} / \mathrm{min}$ powder addition, $v$ laser beam $=900 \mathrm{~mm} / \mathrm{min}$, a) etching with Kalling'2 reagent $b$ ) etching with Beeraha'2 reagent

Quantitative phase analyses were effectuated on micrographs recorded in high resolution $(\mathrm{N}=500 \mathrm{x})$ made by $\mathrm{J}$ Microvision 1.2.7 image analysis software. The results of 10-14 micrographs executed in original magnifications were summarized at each specimen. The number of micrograph depends on dimensions of weld metals.

The effects of additional materials on mechanical properties and on corrosion resistance were studied. The mechanical tensing tests were effectuated by Instron 8872 instrument. In this work the laser beam welding technology influence on the corrosion resistance were studied according to ASTM G48.

\subsection{Microstructure of Laser Butt Welds}

Although for the studied DSS samples the specific heats are same, the thermal conductivity are similar [12] the weld metal shapes differ at different parent materials qualities (Fig. 3).
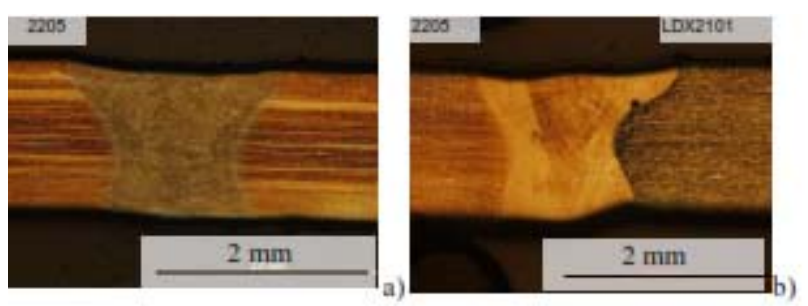

Fig. 3 Effects of parent materials on weld metals characteristics Vlaser beam $=1500 \mathrm{~mm} / \mathrm{min}$, Beraha'2 reagent,

a) 2205 autogenously welding. b) 2205-LDX2101 heterogenic autogenously welding.
The weld depth to width ratio $(\mathrm{D} / \mathrm{W})$ is determined by the heat transport mode in the molten pool. The ratio of the weld depth to width increase with welding speed in case of homogenous welding joins (Fig. 4), as it was expected [18].

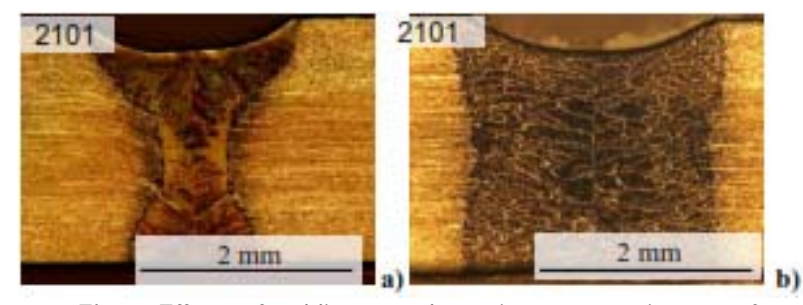

Fig. 4Effects of welding speed on microstructure in case of autogenously welding, Beraha'2 reagent, LDX2101/ 2.5 samples

a) $V_{\text {laser beam }}=1800 \mathrm{~mm} / \mathrm{min}$ b) $V_{\text {laser beam }}=750 \mathrm{~mm} / \mathrm{min}$

Studying the microstructures of the metallographic prepared samples it was observed that the columnarregular structure appears in case of laser beam welding without additional material. The grain shape (roundness) is modified by cooling rate. Decreasing of laser beam speed the roundness of the solidified grain increased and the quantity of fine dispersed austenite island (light ) inside of ferrite grains (darken) matrix increased (Fig. 5).
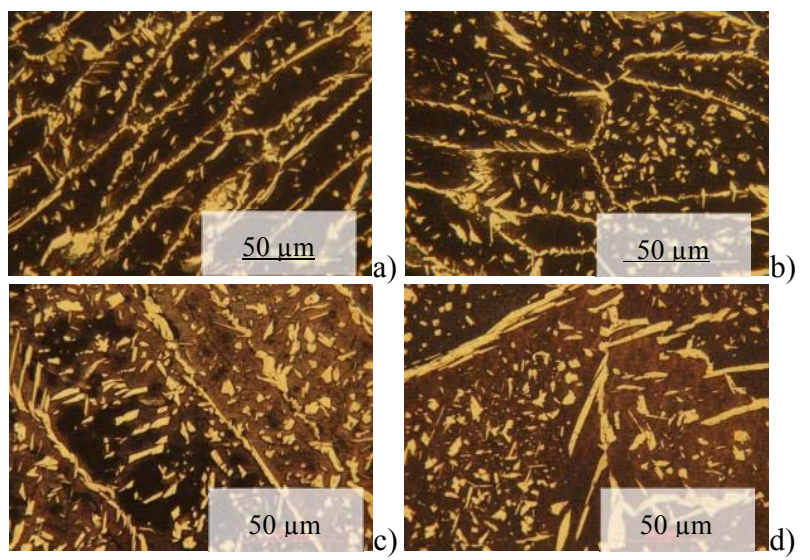

Fig. 5 Laser beam speed effect on the microstructure of weld metal at LDX2101/ 1.5 samples after autogeneous welding Beraha'2 reagent a) $v_{\text {laser }}=3000 \mathrm{~mm} / \mathrm{min} \mathrm{b}$ ) $v_{\text {laser }}=3000 \mathrm{~mm} / \mathrm{min}$ central region of weld metal c) $v_{\text {laser }}=1500 \mathrm{~mm} / \mathrm{min} \mathrm{d}$ ) $v_{\text {laser }}=750 \mathrm{~mm} / \mathrm{min}$

No significant differences have been registered in ferrite content due to welding speed in case of autogenously welding (Fig. 6).

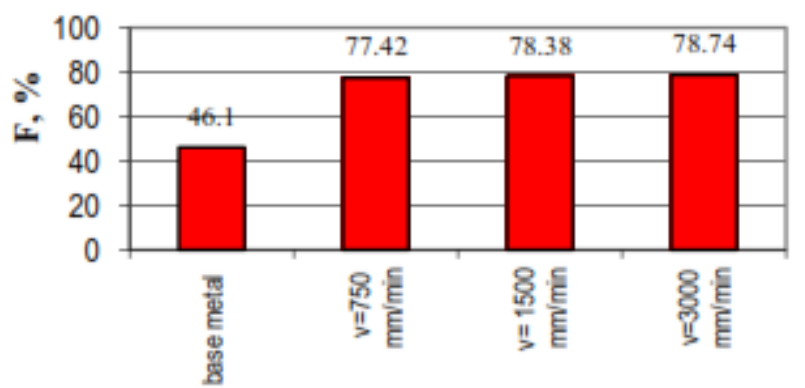

Fig. 6 Laser beam speed effect on the ferrite content of weld metals at LDX2101/ 1.5 samples after autogeneous welding 
Adjusting laser focus spot on specimens' surfaces correspondent welded joints have been produced in case of autogenously welding and when have been applied powder addition at all studied thickness. Applying 1500 $\mathrm{mm} / \mathrm{min}$ laser beam speed correspondent joints were obtained both in case of autogenously welding as welding with filler materials at sheets with $1.5 \mathrm{~mm}$ thickness. Applying additional material the geometrical characteristics of weld metals differs from the autogenously weld metals shapes even if the welding speed and the base materials were same (Fig. 7).
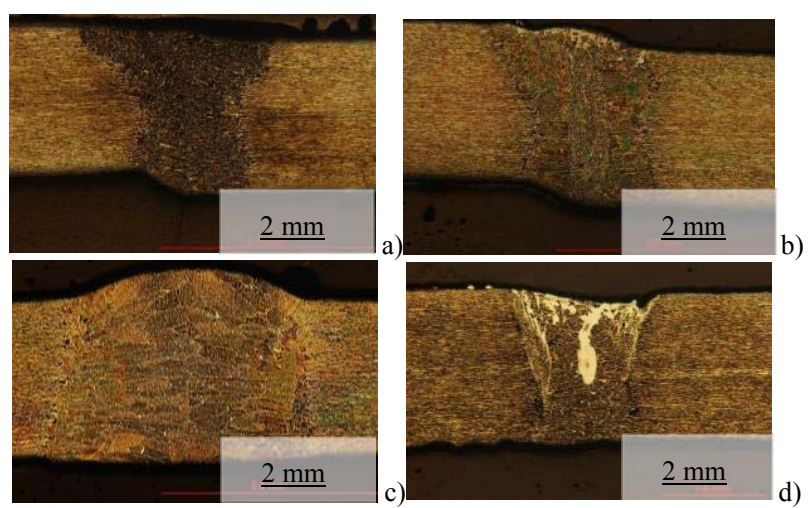

$2 \mathrm{~mm}$ d)

Fig.7 Effects of additional materials on weld join characteristics at 2101 samples with $1.5 \mathrm{~mm}$ thickness,. Beraha'2 reagent

a) autogenous welding Vlaser beam $=1500 \mathrm{~mm} / \mathrm{min}$ b) $14 \mathrm{~g} / \mathrm{min}$ powder addition, Vlaser beam $=1500 \mathrm{~mm} / \mathrm{min}$ c) wire addition $v_{\text {wire }}=1000 \mathrm{~mm} / \mathrm{min}$

$$
\text { Vlaser beam }=1500 \mathrm{~mm} / \mathrm{min} \text { d) } 14 \mathrm{~g} / \mathrm{min} \text { powder addition, Vlaser beam }=2400
$$

Etching with Beraha'2 reagent the light austenitic phase is well distinguishable from ferrite in micrographs. Fig. 7 and 8 show that Metco $41 \mathrm{C}$ powder addition can result austenite excess at faces of seams. The weld metal microstructure became more inhomogeneous as welding speed had increased (Fig. 7b - d).

Applying additional materials the welding speed had to be reduced for correspondent welding joint, in comparison to autogenously welding, at specimens with $2.5-3 \mathrm{~mm}$ thickness. Central planar solidifications were observed at autogenously welded specimens. When additional materials had been applied the planarity of central solidification zones modified.

Central equiaxed grains zones appeared when power addition had been used. The microstructure of weld metal changed because the flowing mode had been modified, by introducing high nickel content material.

At samples with $2.5-3 \mathrm{~mm}$ thickness good square butt welding joints appeared when the focus plane were right at the surface both at samples autogenously welded such in case of laser beam welding with powder addition. In case of welding with filler wire full penetration welds without weld defects were obtained with 4- $6 \mathrm{~mm}$ focus depth optics system [19]. The heat affected zones became narrow (1-3 equiaxed grain rows) in each case (Fig. 8.-9). The metallurgy of welded duplex stainless steel is principally determined by the weld metal composition [20]. In weld metals austenite appear on grain boundaries and inside of grains as islands in ferritic matrix in each case, only the distribution, and the sizes of austenite islands will modify due to the processes and parent materials (Fig. 9).
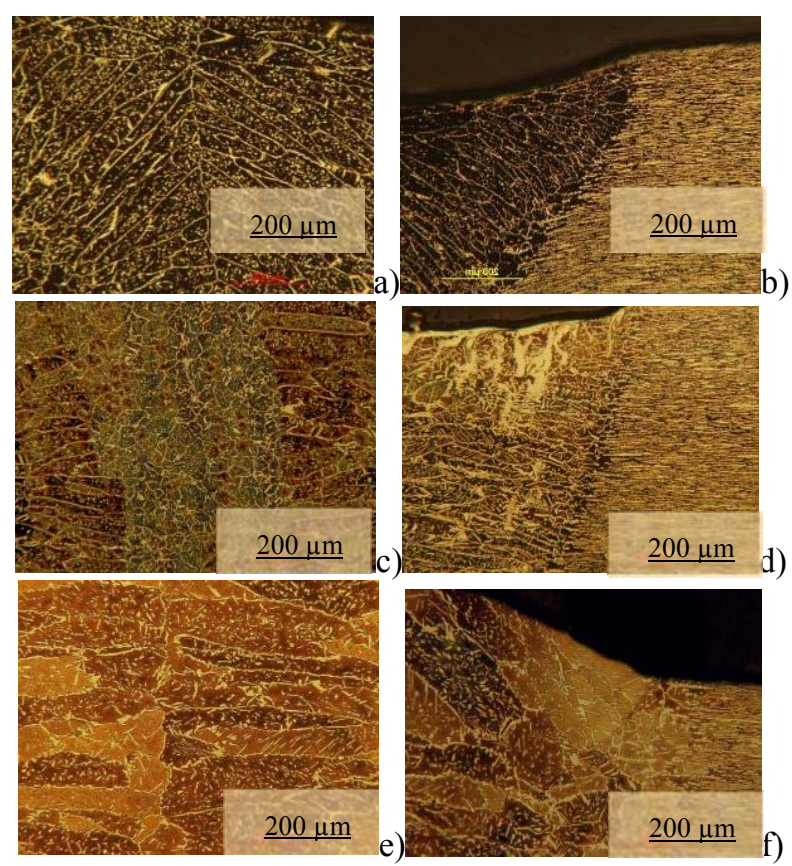

Fig.8 Additional materials effect on the microstructure of welded zones at LDX2101 1.5 samples. $N_{\text {orig }}=100 \times v=1500 \mathrm{~mm} / \mathrm{min}$ a) central region of weld metal after autogenously welding b) HAZ autogenously welding, c) central region of weld metal at $14 \mathrm{~g} / \mathrm{min}$ powder addition, d) $\mathrm{HAZ}$ at $14 \mathrm{~g} / \mathrm{min}$ powder addition, e) central region after wire addition, $v$ wire laser beam $=1000 \mathrm{~mm} / \mathrm{min} \mathrm{f}$ ) HAZ at $v_{\text {wire }}=1000 \mathrm{~mm} / \mathrm{min}$
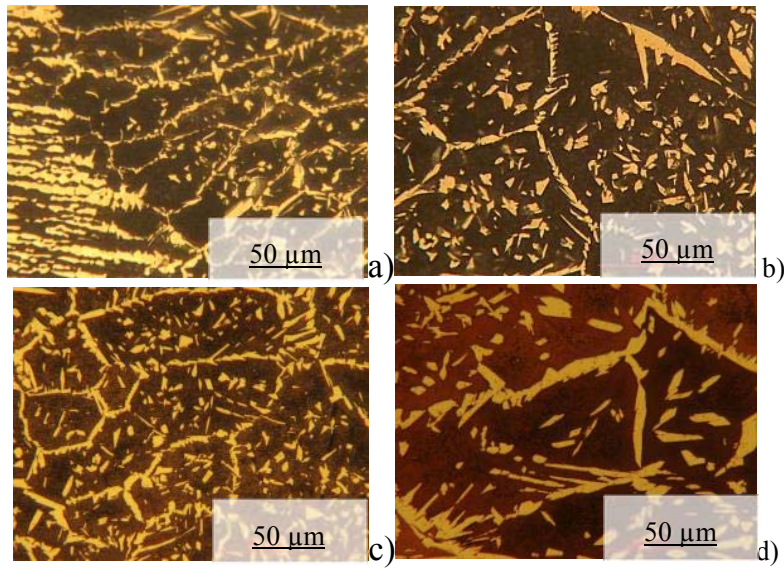

Fig.9 Additional materials effect on the microstructure of welded zones at LDX2101/ 1.5 samples. Vlaser beam $=1500 \mathrm{~mm} / \mathrm{min} N=500 x$ a) HAZ after autogenously welding b) central region of weld metal at face, after autogenously welding, c) central region of weld metal at 14 $\mathrm{g} / \mathrm{min}$ powder addition, d) wire addition $v_{\text {wire orig }}=1000 \mathrm{~m} / \mathrm{min}$

Additional materials effects on ferrite / austenite ratio at the studied specimens can be seen in Fig. 10. The weld metals ferrite content comparisons were effectuated on specimens with correspondent joints, and where the welding parameters were similar as far as possible. The specimens which were welded with powder addition contain more austenite at face of the weld metal than in 
other zones even if powder addition speed was $14 \mathrm{~g} / \mathrm{min}$. For this reason the ferrite content were studied separate at the faces zones from the rest of weld metals in quantitative analyses at the specimens welded with Metco 21C powder additions (Fig. 10). At specimens with 1.5 $\mathrm{mm}$ thicknesses were compared the samples welded with $1500 \mathrm{~mm} / \mathrm{min}$ laser beam speed.

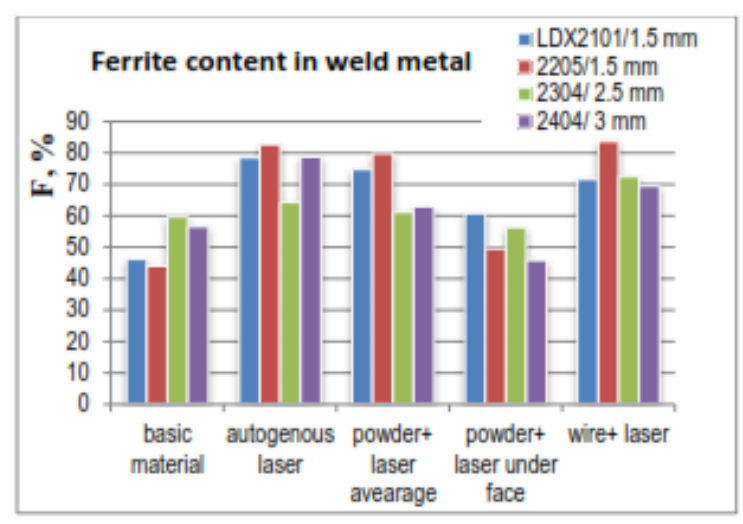

Fig.10 Parent material and welding parameters effect on ferrite content in weld metal

The ferrite contents of weld metals at 2205 standard duplex specimens increased to $80 \%$ during of laser beam welding. The additional welding materials had no high effect on ferrite content of weld seam at this standard duplex steel.

At LDX2101 lean duplex specimens the $2293 \mathrm{LN}$ wire addition had the most positive effect on austenite content of the weld metal. In cases of 2304 and 2404 DSSs specimens the least ferrite content of weld seams were obtained at specimens welded with Metco 41C powder additions, not only in the faces zones but on the homogenous zones also.

The mechanical and corrosion properties of stainless steels welds are believed to be highly dependent on microstructure [18], [20]-[23]

\subsection{Mechanical Properties of Laser Butt Welds}

The transverse tensile tests were executed conform MSZ EN ISO 4136:2013. The tests results can be seen in Fig. 11. Good correspondence between ferrite content and tensile strength could be detected at samples with homogenous weld metals. Even if the lowest ferrite content were observed at specimens welded with powder additions, the best ductility were observed at the samples welded with filler wire additions.

The autogenously laser welded specimens had the lowest ductility and strength even if in some cases, such as standard duplex stainless steel (2205), no big difference were observed in tensile strength and ductility at samples welded with or without additional material. In case of studied lean duplex stainless steels the additional materials favourable effect is representative. At autogenously welded LDX2101 specimens' tensile strength and percentage of total elongation at fracture were low even though the weld metal geometry at the metallographic studied samples was similar with standard 2205 sample as it can be seen in Fig. 12. At these specimens near of central planar solidification small undercutting in weld metal were observed. Similar results were obtained when the welding speed had been higher or lower.
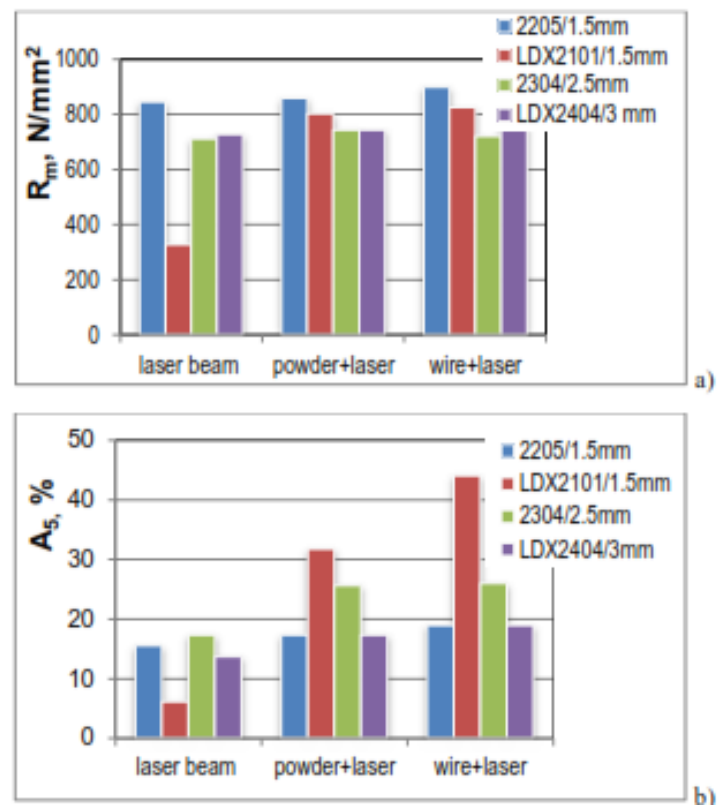

Fig.11 Tensile test results of welded specimens with or without additional materials a)tensile strength b) ductility
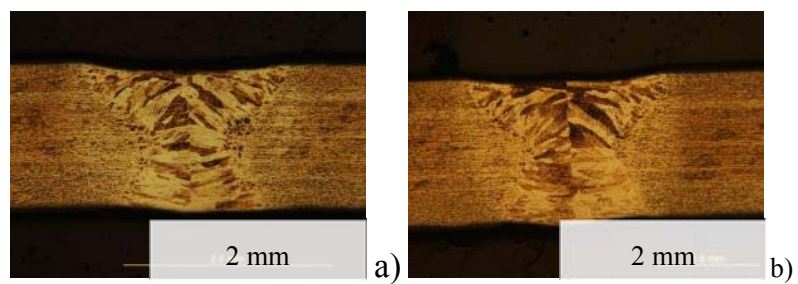

Fig.12 Weld metal appearance at autogenous welded $1.5 \mathrm{~mm}$ thick samples $V$ laser beam $=1500 \mathrm{~mm} / \mathrm{min}$. Etching with Kalling' reagent a) LDX 2101 samples b) 2205 tested samples
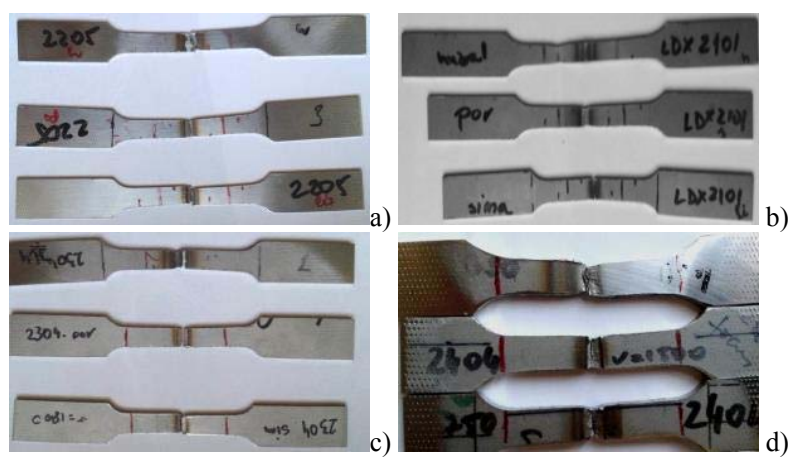

Fig. 13 Some characteristic samples after tensile tests a) 2205 tested samples b) LDX 2101 samples c) 2304 specimens d) 2404 specimens

Fig. 13 shows characteristic tensile tested samples from each studied DSS material. On the photos the upper samples were welded with 2293 NL wire addition, in the 
midle are the samples welded wit austenitical powder addition, the lowers are autogenously welded specimens. The most failures occurred in the weld metal or in the HAZ, while some welded specimens failed in the base metal at higher ductility.

\subsection{Corrosion Resistance}

Even though the chemical composition of autogenously laser welded materials do not changes in comparisons with parent materials, the microstructural modifications can modify the corrosion resistance. To study of pitting corrosion resistance the oxidized surfaces near the seams were departed chemically before the study and ultrasonic cleaned in ethanol. After draying the samples with $10 \mathrm{~mm}$ $\mathrm{x} 25 \mathrm{~mm}$ sizes were put separately into glasses containing $100 \mathrm{~g}$ of ferric chloride hexahydrate $\left(\mathrm{FeCl}_{3} \times 6 \mathrm{H}_{2} \mathrm{O}\right)$ in 900 $\mathrm{ml}$ of distilled water, conform ASTM G48.

Studying the corrosion behaviour of the weld joints it was observed that pitting corrosion appeared on the weld metal surfaces and on heat affected zones (Fig. 14). The pitting appearances were intensive at lean duplex stainless steels. At standard 2205 steel few pitting appeared.

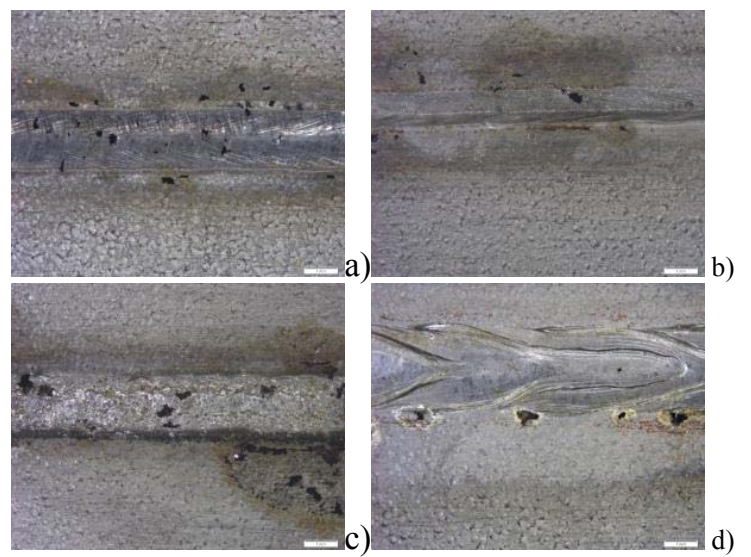

Fig.14. Pitting corrosion appearance at LDX2101 material

a) face of autogenously welded joint b) root of autogenously welded sample c) c) powder addition d) wire addition

The weight changing was measured after $24 \mathrm{~h}, 48 \mathrm{~h}$ and $72 \mathrm{~h}$. Fig. 15 shows the mass loss measured after 72 hours are presented. The additional welding materials increased the corrosion resistance. At all studied materials the less mass loss were produced at joints which were done by $2293 \mathrm{NL}$ wire addition. The most mass loss were observed at autogenously laser beam welding with exception of LDX2101 lean duplex samples, where the most mass loss was measured at welding with Metco $41 \mathrm{C}$ powder. There is the possibility of a galvanic reaction (dissimilar metal).

The most resistant samples were the laser welded sheets with high nickel and molybdenum content. The mass loss of 2205 autogenously welded sample was $15.85 \mathrm{~g} / \mathrm{m}^{2}$, the sample obtained after Metco 41C powder addition loss $6.22 \mathrm{~g} / \mathrm{m}^{2}$ after 72 hours in room temperature, and only $3.58 \mathrm{~g} / \mathrm{m}^{2}$ loss the sample welded with wire addition (Fig. 16).

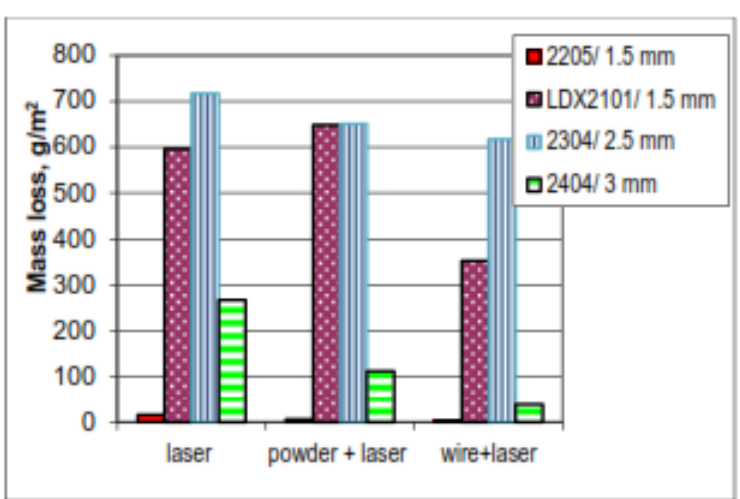

Fig. 15. Corrosion mass loss of welded samples with different welding material addition

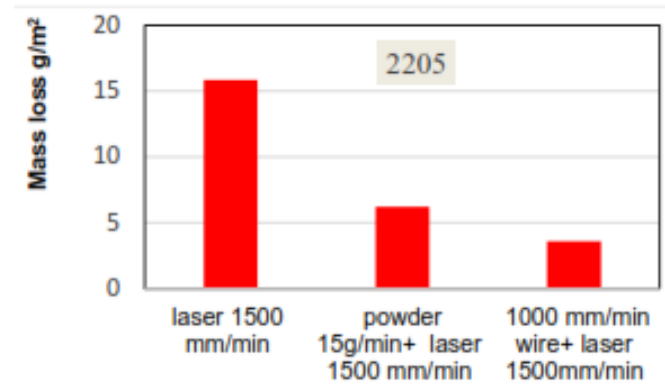

Fig. 16. Corrosion mass loss of welded samples with different additional material at standard duplex stainless steel after 72 hours

\section{CONCLUSION}

Heat input affects straight on the cooling rate of the weld and there by ferrite-austenite ratio. Laser welding of duplex grades has been associated with excessively high ferrite contents, due to the low heat input and rapid cooling rate. The heat inputs can be modified by welding speed, focus point of laser beam and by additional materials. The additional materials affect the laser welded seam microstructure.

The least ferrite content at each material was obtained by Metco 21C power addition, but in general the best elongations were obtained on the welded samples witch were welded using $2293 \mathrm{NL}$ filler wire, conventional used for standard duplex stainless steels. Welding consumable addition has positive effect on mechanical proprieties.

The best pitting corrosion resistance were obtained at samples which were laser welded with welding wire addition at each material. The parent materials effect (PRE number) was observed in corrosion tests. The inhomogeneous weld seam is not favourable from point of view of corrosion resistance.

\section{ACKNOMLDGEMENTS}

The author thank for the financial support given by the PROJECT EFOP-3.6.1-16-2016-00010. 


\section{REFERENCES}

[1] Okano, S., Tsuji H., Mochizuki M. (2017) Temperature distribution effect on relation between welding heat input and angular distortion. Sci. Technol. Weld. Join. 22, pp.59-65

[2] Tóth L., Haraszti F.,.Kovács T, (2018): Heat treatment effect for stainless steel corrosion resistance, European Journal of Material Science and Engineering,.3/2, pp.38-42.

[3] Krishnan K. N., Prasad Rao K. (1990): Effect of ferrite content and weld heat input on the room temperature stress corrosion cracking resistance of austenitic clad metals. Materials and Corrosion, 41/14, pp.178-184,

[4] Shaikh H., Anita T., Poonguzhali A., Dayal R.K and Raj, B. (2011). Stress corrosion cracking (SCC) of austenitic stainless and ferritic steel weldments, Stress Corrosion Cracking, 10.1533/9780857093769.3.427, pp.427-484.

[5] Haraszti F.,Kovács T. (2017): Plastic deformation effect of the corrosion resistance in case of austenitic stainless steel, IOP Conference Series: Materials Science and Engineering 175: Paper 012048. 4.

[6] Gunn RN. (1999): Duplex stainless steels. Abington Publishing, Cambridge, p:1-47, 110-143.

[7] Nilsson J.(1992): Super duplex stainless steels. Materials Science and Technology, 8. pp. 685-700.

[8] Nilsson J., Kangas P, Karlsson T., Wilson A. (2000): A. Mechanical properties, microstructural stability and kinetics of $\sigma$ phase formation in 29Cr6Ni-2Mo-0.38N super duplex stainless steel. Metallurgical and Materials Transactions A., 31. pp. $35-40$.

[9] Karlsson L, Ryen L, Pak S. ( 1995): Precipitation of intermetallic phases in $22 \% \mathrm{Cr}$ duplex stainless weld metals. Welding Journal. 74. pp.28-40.

[10] Liljas M.( 1994) The welding metallurgy of duplex stainless steels, Proceedings of 4th International Conference on Duplex Stainless Steels, Glasgow, Scotland, 15pp.

[11] Pekkarinen J., Kujanpää V.( 2010): The effects of laser welding parameters on the microstructure of ferritic and duplex stainless steels welds. Physics Procedia., 5. pp.517-523.

[12] https://www.imoa.info/download_files/stainlesssteel/Duplex_Stainless_Steel_3rd_Edition.pdf
[13] http://steelfinder.outokumpu.com/ GradeDataSheetv3PDF.aspx?OKGrade $=$ LDX $\% 202$ 404\&Category $=$ Forta

[14] Zhang Z., Jing H., Xu L., Han Y., Zhao L., Zhou C. (2017): Effects of nitrogen in shielding gas on microstructure evolution and localized corrosion behaviour of duplex stainless steel welding joint, Applied Surface Science.404,, pp 110-128,

[15] Yan R.L. Wu Y., Hua X. (2016) :Influence of absorbed nitrogen on microstructure and corrosion resistance of 2205 duplex stainless steel joint processed by fiber laser welding, Journal of Materials Processing Technology. 231, pp 397-405.

[16] Westin E.M., Johansson M.M., Bylund L.-A.A., Pettersson R.F.A. (2014): Effect on microstructure and properties of super duplex stainless steel welds when using backing gas containing nitrogen and hydrogen. Weld. World. 58, 347-354.

[17] Varbai B., Májlinger K. (2018):Thermoelectric Power Measurements on Duplex Stainless Steel Weldments Vehicle and Automotive Engineering 2. VAE 2018. Lecture Notes in Mechanical Engineering. Springer, Cham.

[18] Batahgy A. M El-,Khourshid A.F., Sharef T. (2011): Effect of Laser Beam Welding Parameters on Microstructure and Properties of Duplex Stainless Steel, Materials Sciences and Applications, 2, pp 14431451

[19] Fabian E.R, Dobranszky J., CsizmaziaJ., Ott R. (2017): Effect of Laser Beam Welding on the Microstructure of Duplex Stainless Steels, Mat. Sci. Forum. 885, pp 245-250

[20] Westin E., Fellman A. (2010). Effect of laser and laser hybrid welding on the corrosion performance of a lean duplex stainless steel. Journal of Laser Applications. 22/4. pp. 150- 158.

[21] Na G.H,, Jung W.Y., Ha Y., (2012) Microstructure and Mechanical Properties of Duplex Stainless steel for Anchor Bolt Application, International. Journal of Materials and Metallurgical Engineering. 6/10.

[22] Labanowski J, Świerczyńska A, Topolska S. (2014): Effect of microstructure on mechanical properties and corrosion resistance of 2205 duplex stainless steel, Polish Maritime Research 4(84), 21, pp. 108-112,

[23] Nilsson J.O., Wilson A. (1993): Influence of isothermal phase transformations on toughness and pitting corrosion of duplex stainless steel SAF 2507. Materials Science and Technology, 9, pp.545-554. 